University of Nebraska - Lincoln

DigitalCommons@University of Nebraska - Lincoln

\title{
Electron and hole traps in Ag-doped lithium tetraborate (Li2B407) crystals
}

A. T. Brant

West Virginia University

B. E. Kananan

Air Force Institute of Technology, Wright-Patterson Air Force Base, Ohio

M. K. Murari

University of Cincinnati

J. McClory

Air Force Institute of Technology, Wright Patterson Air Force Base, $\mathrm{OH}$

J. C. Petrosky

Air Force Institute of Technology, James.Petrosky@afit.edu

See next page for additional authors

Follow this and additional works at: https://digitalcommons.unl.edu/physicsdowben

Part of the Physics Commons

Brant, A. T.; Kananan, B. E.; Murari, M. K.; McClory, J.; Petrosky, J. C.; Adamiv, V. T.; Burak, Ya. V.; Dowben, Peter A.; and Halliburton, L. E., "Electron and hole traps in Ag-doped lithium tetraborate (Li2B4O7) crystals" (2011). Peter Dowben Publications. 247.

https://digitalcommons.unl.edu/physicsdowben/247

This Article is brought to you for free and open access by the Research Papers in Physics and Astronomy at DigitalCommons@University of Nebraska - Lincoln. It has been accepted for inclusion in Peter Dowben Publications by an authorized administrator of DigitalCommons@University of Nebraska - Lincoln. 


\section{Authors}

A. T. Brant, B. E. Kananan, M. K. Murari, J. McClory, J. C. Petrosky, V. T. Adamiv, Ya. V. Burak, Peter A. Dowben, and L. E. Halliburton 


\title{
Electron and hole traps in Ag-doped lithium tetraborate $\left(\mathrm{Li}_{2} \mathrm{~B}_{\mathbf{4}} \mathrm{O}_{\mathbf{7}}\right)$ crystals
}

\author{
A. T. Brant, ${ }^{1}$ B. E. Kananan, ${ }^{2}$ M. K. Murari, ${ }^{3}$ J. W. McClory, ${ }^{2, a)}$ J. C. Petrosky, ${ }^{2}$ \\ V. T. Adamiv, ${ }^{4}$ Ya. V. Burak, ${ }^{4}$ P. A. Dowben, ${ }^{5}$ and L. E. Halliburton ${ }^{1}$ \\ ${ }^{1}$ Department of Physics, West Virginia University, Morgantown, West Virginia 26506, USA \\ ${ }^{2}$ Department of Engineering Physics, Air Force Institute of Technology, Wright-Patterson Air Force Base, \\ Ohio 45433, USA \\ ${ }^{3}$ Department of Geology, University of Cincinnati, Cincinnati, Ohio 45221, USA \\ ${ }^{4}$ Institute of Physical Optics, 23 Dragomanov St., Lviv 79005, Ukraine \\ ${ }^{5}$ Department of Physics and Astronomy, Nebraska Center for Materials and Nanoscience, \\ University of Nebraska, Lincoln, Nebraska 68588, USA
}

(Received 17 August 2011; accepted 28 September 2011; published online 10 November 2011)

\begin{abstract}
Electron paramagnetic resonance (EPR), electron-nuclear double resonance (ENDOR), and thermoluminescence (TL) are used to characterize the primary electron and hole trapping centers in a lithium tetraborate $\left(\mathrm{Li}_{2} \mathrm{~B}_{4} \mathrm{O}_{7}\right)$ crystal doped with $\mathrm{Ag}$. Three defects, two holelike and one electronlike, are observed after exposure at room temperature to $60 \mathrm{kV}$ x-rays. The as-grown crystal contains both interstitial $\mathrm{Ag}^{+}$ions and $\mathrm{Ag}^{+}$ions substituting for $\mathrm{Li}^{+}$ions. During the irradiation, substitutional $\mathrm{Ag}^{+}$ions $\left(4 \mathrm{~d}^{10}\right)$ trap holes and two distinct $\mathrm{Ag}^{2+}$ centers $\left(4 \mathrm{~d}^{9}\right)$ are formed. These $\mathrm{Ag}^{2+}$ EPR spectra consist of doublets (i.e., the individual ${ }^{107} \mathrm{Ag}$ and ${ }^{109} \mathrm{Ag}$ hyperfine lines are not resolved). One of these hole centers is an isolated unperturbed $\mathrm{Ag}^{2+}$ ion and the other is a $\mathrm{Ag}^{2+}$ ion with a nearby perturbing defect. EPR and ENDOR angular-dependence data provide the $g$ matrix and the ${ }^{107} \mathrm{Ag}$ and ${ }^{109} \mathrm{Ag}$ hyperfine matrices for the more intense isolated hole center. In contrast, the electronlike EPR spectrum produced during the irradiation exhibits large nearly isotropic hyperfine interactions with ${ }^{107} \mathrm{Ag}$ and ${ }^{109} \mathrm{Ag}$ nuclei and a neighboring $\mathrm{I}=3 / 2$ nucleus (either ${ }^{7} \mathrm{Li}$ or ${ }^{11} \mathrm{~B}$ ). This spectrum is assigned to a trapped electron shared between an interstitial $\mathrm{Ag}$ ion and the substitutional $\mathrm{I}=3 / 2$ ion. Upon warming, the radiation-induced trapped electrons and holes seen with EPR recombine between 100 and $200{ }^{\circ} \mathrm{C}$, in agreement with a single strong TL peak observed near $160{ }^{\circ} \mathrm{C}$. (C) 2011 American Institute of Physics. [doi:10.1063/1.3658264]
\end{abstract}

\section{INTRODUCTION}

Lithium tetraborate $\left(\mathrm{Li}_{2} \mathrm{~B}_{4} \mathrm{O}_{7}\right)$ crystals doped with $\mathrm{Ag}$ are excellent candidates for radiation-detection applications involving light emission. ${ }^{1-6}$ Large high-quality single crystals with controlled doping can be readily grown and their impurity-related radiative processes can be extremely efficient. ${ }^{7-13}$ Another important feature of $\mathrm{Li}_{2} \mathrm{~B}_{4} \mathrm{O}_{7}$ crystals is the presence of two isotopes $\left({ }^{6} \mathrm{Li}\right.$ and $\left.{ }^{10} \mathrm{~B}\right)$ with large cross-sections for thermal neutron capture. ${ }^{14-17}$ Crystals enriched with these isotopes may be used in applications involving neutron detection.

As with all radiation-detector materials, it is important to investigate the point defects, both intrinsic (vacancies, interstitials, and antisites) and extrinsic (intentional or unintentional impurities), which may affect the device performance. Depending on the operating temperature of a device, these defects can act as transient or long-lived electron and hole traps. In some cases, the defects provide new and highly efficient radiative recombination pathways, whereas in other cases they introduce nonradiative recombination pathways that limit the amount of emitted light. For $\mathrm{Li}_{2} \mathrm{~B}_{4} \mathrm{O}_{7}$ crystals, the goals are to identify the active point defects, to establish their possible charge states, and to determine the thermal stability of each charge state. In a recent study, ${ }^{18}$ the primary

\footnotetext{
a) Author to whom correspondence should be addressed. Electronic mail: John.McClory@afit.edu.
}

intrinsic electron and hole traps in x-ray-irradiated undoped $\mathrm{Li}_{2} \mathrm{~B}_{4} \mathrm{O}_{7}$ crystals were identified as oxygen and lithium vacancies, respectively. That work and the earlier detailed investigations of $\mathrm{Cu}^{2+}$ ions in $\mathrm{Li}_{2} \mathrm{~B}_{4} \mathrm{O}_{7}$ crystals ${ }^{9,19-22}$ provide the background information for a comprehensive study of electron and hole traps in $\mathrm{Ag}$-doped crystals.

In the present paper, a $\mathrm{Li}_{2} \mathrm{~B}_{4} \mathrm{O}_{7}$ crystal doped with $\mathrm{Ag}$ is exposed to ionizing radiation at room temperature. Electron paramagnetic resonance (EPR) and electron-nuclear double resonance (ENDOR) are used to characterize the filled electron and hole traps. Before the irradiation, a portion of the $\mathrm{Ag}$ ions are present as nonparamagnetic $\mathrm{Ag}^{+}$ions $\left(4 \mathrm{~d}^{10}\right)$ replacing $\mathrm{Li}^{+}$ions. During the irradiation, these substitutional $\mathrm{Ag}^{+}$ions trap holes and two distinct EPR spectra identified as $\mathrm{Ag}^{2+}$ ions $\left(4 \mathrm{~d}^{9}\right)$ are subsequently observed at low temperature. A series of EPR and ENDOR spectra taken with the magnetic field along the high-symmetry directions provide a complete set of spin-Hamiltonian parameters for the more intense of the two $\mathrm{Ag}^{2+}$ hole traps (labeled center A). The exposure to ionizing radiation at room temperature also produces an electronlike EPR spectrum that is assigned to an interstitial $\mathrm{Ag}$ ion sharing an unpaired electron with a neighboring substitutional ion that has an $I=3 / 2$ nuclear spin (either ${ }^{7} \mathrm{Li}$ or ${ }^{11} \mathrm{~B}$ ). This latter defect has little angular dependence and only the parameters describing its [001] EPR spectrum are reported. These radiation-induced electron and hole traps become thermally unstable when the crystal is heated above room temperature. The three EPR signals 
disappear together in the $100-200{ }^{\circ} \mathrm{C}$ range. Their thermally induced decay correlates with an intense thermoluminescence (TL) peak near $160^{\circ} \mathrm{C}$.

\section{EXPERIMENTAL}

The Ag-doped single crystal of $\mathrm{Li}_{2} \mathrm{~B}_{4} \mathrm{O}_{7}$ used in the present investigation was grown by the Czochralski technique at the Institute of Physical Optics (L'viv, Ukraine). Oriented samples with approximate dimensions of $1 \times 5 \times 3$ $\mathrm{mm}^{3}$ were cut from the larger boule and used in the EPR, ENDOR, and TL experiments. $\mathrm{Li}_{2} \mathrm{~B}_{4} \mathrm{O}_{7}$ crystals are tetragonal (the space group is $I 4_{1} c d$ and the point group is $4 \mathrm{~mm}$ ) with lattice constants $a=9.475 \AA$ and $c=10.283 \AA$ at room temperature. ${ }^{23-27} \mathrm{~A}$ unit cell in this crystal contains 104 atoms (eight formula units) and the basic repeating structural building block is a $\left(\mathrm{B}_{4} \mathrm{O}_{9}\right)^{6-}$ anionic group. Figure 1 shows this building block along with one adjacent $\mathrm{Li}^{+}$ion and its additional neighboring oxygen ions. In this lattice, there are two inequivalent boron sites and four inequivalent oxygen sites. All of the lithium sites are crystallographically equivalent. Both $\mathrm{BO}_{3}$ and $\mathrm{BO}_{4}$ units are present. Each oxygen ion has two boron neighbors, and each lithium ion has five oxygen neighbors. The bond lengths and separation distances for the ions shown in Fig. 1 are listed in Table I of Ref. 18.

EPR data were taken with a Bruker EMX spectrometer and ENDOR data were taken with a Bruker E-500 spectrometer. Both spectrometers operated near 9.5 GHz. Helium-gasflow systems were used to control the sample temperature and proton NMR gaussmeters were used to measure the static magnetic field. A small $\mathrm{Cr}$-doped $\mathrm{MgO}$ crystal was used to correct for the difference in magnetic field between the sample and the probe tips of the gaussmeters (the isotropic $\mathrm{g}$ value for $\mathrm{Cr}^{3+}$ in $\mathrm{MgO}$ is 1.9800). An x-ray tube operating at $60 \mathrm{kV}$ and $30 \mathrm{~mA}$ was used to convert a portion of the $\mathrm{Ag}^{+}$ions in the $\mathrm{Li}_{2} \mathrm{~B}_{4} \mathrm{O}_{7}$ crystal to the observed paramagnetic charge states. Irradiation times were $10 \mathrm{~min}$. An asgrown sample was clear to the eye and had no EPR signals. After an x-ray irradiation at room temperature, the sample appeared light green. Intensities of the EPR spectra indicate that the combined concentration of $\mathrm{Ag}^{2+}$ trapped hole centers in our irradiated crystal is approximately $5 \times 10^{17} \mathrm{~cm}^{-3}$. This estimate is based on comparisons with a calibrated

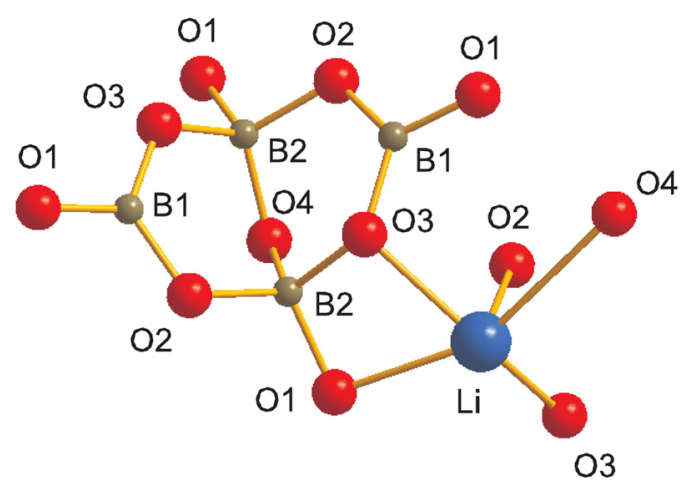

FIG. 1. (Color online) Schematic representation of a portion of the $\mathrm{Li}_{2} \mathrm{~B}_{4} \mathrm{O}_{7}$ crystal. The five oxygen ions surrounding a lithium site are illustrated along with the basic $\mathrm{B}_{4} \mathrm{O}_{9}$ group. This view is along an arbitrary direction. weak pitch EPR sample from Bruker. The concentration of $\mathrm{x}$-ray-induced Ag-related electron traps is similar.

Thermoluminescence data were taken at the University of Cincinnati using a Ris $\varnothing$ TL/OSL reader (Model DA-20) in the laboratory of Professor Lewis Owen. An internal ${ }^{90} \mathrm{Sr} /{ }^{90} \mathrm{Y}$ beta source was used to irradiate the sample at room temperature (the exposure time was $5 \mathrm{~s}$ and the quartzequivalent dose rate was approximately $0.1 \mathrm{~Gy} / \mathrm{s}$ ). Emitted light was detected with a bi-alkali EMI 9235QA photomultiplier tube. Hoya U340 and Schott BG39 filters were placed between the sample and the photomultiplier tube, thus restricting the detected light to the $300-400 \mathrm{~nm}$ range.

\section{RESULTS AND DISCUSSION}

Ionizing radiation (x-rays) is used to produce large concentrations of paramagnetic defects in the Ag-doped $\mathrm{Li}_{2} \mathrm{~B}_{4} \mathrm{O}_{7}$ crystal. The $\mathrm{x}$-rays randomly produce pairs of electrons and holes in the lattice. Many of these electrons and holes immediately recombine, radiatively or nonradiatively, to restore the original lattice; however, a portion of the electrons and holes migrate sufficiently far from each other and encounter a stabilizing entity, such as a vacancy or an impurity. This allows a few of the electrons and holes to become "trapped" at widely separated sites in the crystal and form the observed stable paramagnetic point defects. The following results show that $\mathrm{Ag}$ ions act as both electron and hole traps in $\mathrm{Ag}$-doped $\mathrm{Li}_{2} \mathrm{~B}_{4} \mathrm{O}_{7}$ crystals. This contrasting behavior occurs because $\mathrm{Ag}^{+}$ions occupy two distinctly different positions in the as-grown $\mathrm{Li}_{2} \mathrm{~B}_{4} \mathrm{O}_{7}$ crystal. The $\mathrm{Ag}^{+}$ions substituting for $\mathrm{Li}^{+}$ions act as hole traps while the $\mathrm{Ag}^{+}$ions at interstitial sites act as electron traps.

\section{A. Trapped hole centers $\left(\mathrm{Ag}^{2+}\right.$ ions)}

Two holelike centers are formed in the Ag-doped $\mathrm{Li}_{2} \mathrm{~B}_{4} \mathrm{O}_{7}$ crystal during the $\mathrm{x}$-ray irradiation at room-temperature. Figure 2 shows the EPR spectrum taken at $15 \mathrm{~K}$ with the magnetic field along the [001] direction. Each of these $\mathrm{S}=1 / 2$ centers is represented by a pair of equally intense lines. The higher-field pair of lines (labeled center A) is separated by approximately $2.42 \mathrm{mT}$ and the lower-field pair of lines (labeled center B) is separated by approximately $1.93 \mathrm{mT}$. ENDOR results described later in this section verify that hyperfine interactions with $\mathrm{Ag}$ nuclei are responsible for the doublets in Fig. 2. Because their magnetic moments are similar, individual hyperfine lines associated with the ${ }^{107} \mathrm{Ag}$ and ${ }^{109} \mathrm{Ag}$ nuclei are not resolved in the EPR spectra, and only a pair of lines separated by the averaged hyperfine splitting is observed for each holelike center. Separate signals from the two $\mathrm{Ag}$ isotopes are well resolved in the ENDOR data. Combining the ENDOR identification of Ag nuclei with the observed relatively small hyperfine interactions and large positive g shifts allow us to attribute the two holelike defects in Fig. 2 to $\mathrm{Ag}^{2+}$ ions substituting for $\mathrm{Li}^{+}$ions. Center A represents the larger concentration of defects and is assigned to an isolated unperturbed $\mathrm{Ag}^{2+}$ ion in the $\mathrm{Li}_{2} \mathrm{~B}_{4} \mathrm{O}_{7}$ lattice. Center $\mathrm{B}$ is assigned to $\mathrm{a}^{2+}$ ion with a nearby perturbing defect. Possible candidates for this perturbation are $\mathrm{Na}^{+}$or $\mathrm{Ag}^{+}$ions occupying adjacent substitutional lithium sites. 


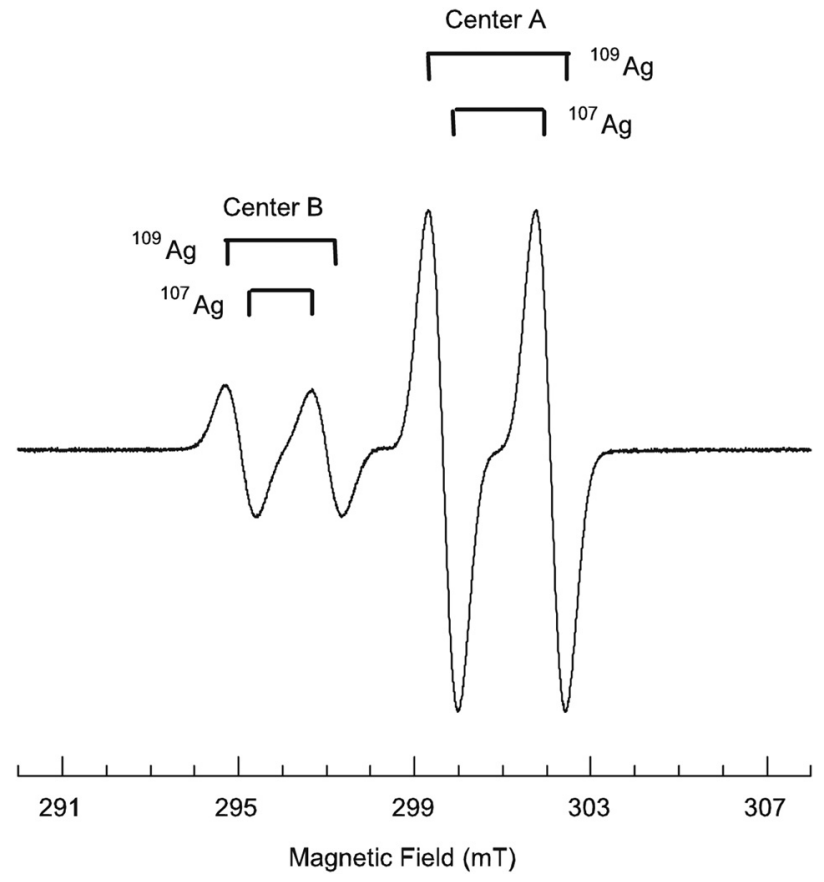

FIG. 2. EPR spectrum showing two similar radiation-induced $\mathrm{Ag}^{2+}$ ions in $\mathrm{Li}_{2} \mathrm{~B}_{4} \mathrm{O}_{7}$ (labeled center $\mathrm{A}$ and center $\mathrm{B}$ ). The data were taken at $15 \mathrm{~K}$ with the magnetic field along the [001] direction. Individual lines due to hyperfine interactions with the ${ }^{107} \mathrm{Ag}$ and ${ }^{109} \mathrm{Ag}$ nuclei are not resolved.

Neutron activation results ${ }^{28}$ show that large concentrations of $\mathrm{Na}$ are present in our $\mathrm{Li}_{2} \mathrm{~B}_{4} \mathrm{O}_{7}$ crystal along with the intentionally large concentrations of $\mathrm{Ag}$. The separation distance in this lattice between a substitutional $\mathrm{Ag}^{2+}$ ion and a neighboring $\mathrm{Na}^{+}$or $\mathrm{Ag}^{+}$ion on $\mathrm{a} \mathrm{Li}^{+}$site is $3.13 \AA$. Surprisingly, we found that center $\mathrm{B}$ is not produced by $\mathrm{x}$-rays at $77 \mathrm{~K}$ (at this lower temperature, the $\mathrm{X}$-rays only produce large concentrations of center A). As the $77 \mathrm{~K}$ irradiated crystal is warmed to room temperature, center $\mathrm{B}$ appears.

The g matrix and the ${ }^{107} \mathrm{Ag}$ and ${ }^{109} \mathrm{Ag}$ hyperfine matrices are determined for center A, the holelike center assigned to the isolated substitutional $\mathrm{Ag}^{2+}$ ion. EPR and ENDOR spectra taken at various orientations of the magnetic field provide input for this process. The $\mathrm{Li}_{2} \mathrm{~B}_{4} \mathrm{O}_{7}$ crystals are tetragonal, with point group $4 \mathrm{~mm}$. Thus, center $\mathrm{A}$ has eight crystallographically equivalent orientations (or sites) in this lattice. These eight crystallographically equivalent sites are all magnetically equivalent when the magnetic field is along the [001] direction and one doublet is observed, as shown in Fig. 2. When the magnetic field is along the [100] or [110] direction, the eight crystallographically equivalent sites separate into two sets of four. The sets are magnetically inequivalent and two doublets are observed for these directions of magnetic field. There are four magnetically inequivalent sets of sites (and thus four doublets) when the magnetic field is rotated in the (010) plane from the [001] to [100] direction. The EPR spectrum taken with the magnetic field along the [101] direction is shown in Fig. 3.

The following spin Hamiltonian, containing only the electron Zeeman term, was used to determine the $g$ matrix for center A.

$$
\mathbf{H}=\beta \mathbf{S} \cdot \mathbf{g} \cdot \mathbf{B} .
$$

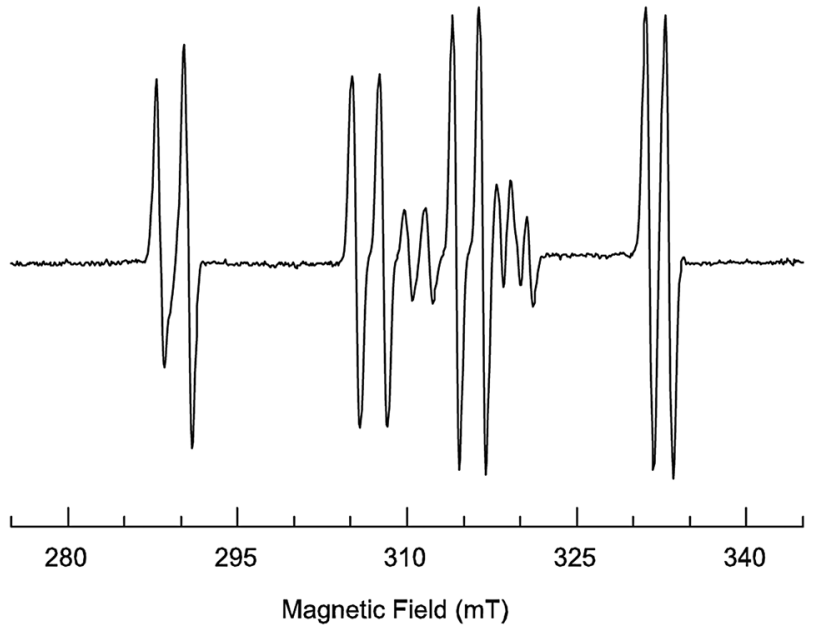

FIG. 3. EPR spectrum of the $\mathrm{Ag}^{2+}$ trapped hole centers. These data were taken at $15 \mathrm{~K}$ with the magnetic field along the [101] direction. The four dominant doublets are associated with center $\mathrm{A}$, the isolated $\mathrm{Ag}^{2+}$ ion. The other less intense doublets in this spectrum are assigned to center B.

The directions of the principal axes of the $g$ matrix do not coincide with the crystal axes. Thus, six parameters are required (three principal values and three Euler angles to specify the directions of the principal axes). EPR spectra taken along the [001], [101], [100], and [110] directions were used to obtain the "best-fit" values for these six parameters. Input data consisted of the mid-points of the nine hyperfine-split doublets observed in these four spectra (i.e., nine magnetic field values and their associated microwave frequencies were used to determine the six parameters). These data included one doublet from the [001] spectrum in Fig. 2, four doublets from the [101] spectrum in Fig. 3, two doublets from the [100] spectrum (not shown), and two doublets from the [110] spectrum (not shown). Our least-squares fitting procedure involved the repeated diagonalization of the $2 \times 2$ Hamiltonian matrix $(S=1 / 2)$ obtained from Eq. (1). Final "best-fit" values of the parameters describing the $g$ matrix are listed in Table I. Our $g$-matrix principal values are in good agreement with the results reported in earlier studies of $\mathrm{Ag}^{2+}$ ions in other crystals. ${ }^{29-31}$ In Table I, the three Euler angles specifying the directions of the principal axes have

TABLE I. Spin-Hamiltonian parameters for center A, the isolated unperturbed $\mathrm{Ag}^{2+}$ trapped-hole center in $\mathrm{Ag}$-doped $\mathrm{Li}_{2} \mathrm{~B}_{4} \mathrm{O}_{7}$ crystals. The $g$ values are obtained from the EPR spectra and the ${ }^{107} \mathrm{Ag}$ and ${ }^{109} \mathrm{Ag}$ values are obtained from the ENDOR spectra. Estimated error limits are \pm 0.0002 for the $g$ values, $\pm 0.03 \mathrm{MHz}$ for the $\mathrm{A}$ values, and $\pm 1.0^{\circ}$ for the angles.

\begin{tabular}{lccccc}
\hline \hline & \multicolumn{2}{c}{ Principal values } & & \multicolumn{2}{c}{ Principal-axis directions } \\
\cline { 2 - 2 } \cline { 5 - 6 } & ${ }^{107} \mathrm{Ag}$ & ${ }^{109} \mathrm{Ag}$ & & $\theta$ & $\phi$ \\
\hline g matrix & & & & & \\
$\mathrm{g}_{1}$ & 2.0439 & & $54.4^{\circ}$ & $76.9^{\circ}$ \\
$\mathrm{g}_{2}$ & 2.1294 & & $73.8^{\circ}$ & $178.9^{\circ}$ \\
$\mathrm{g}_{3}$ & 2.3708 & & $40.2^{\circ}$ & $289.0^{\circ}$ \\
Hyperfine matrix & & & & \\
$\mathrm{A}_{1}(\mathrm{MHz})$ & 42.30 & 49.19 & & $60.0^{\circ}$ & \\
$\mathrm{A}_{2}(\mathrm{MHz})$ & 62.20 & 72.07 & & $82.9^{\circ}$ & $189.4^{\circ}$ \\
$\mathrm{A}_{3}(\mathrm{MHz})$ & 77.05 & 89.12 & & $31.0^{\circ}$ & $285.6^{\circ}$ \\
\hline \hline
\end{tabular}


been converted to $(\theta, \phi)$ pairs, where the polar angle $\theta$ is defined relative to the [001] direction and the azimuthal angle $\phi$ is defined relative to the [100] direction with positive rotation from [100] toward [010] in the (001) plane. The set of principal-axis directions given in Table I for the $g$ matrix corresponds to one of the eight crystallographically equivalent orientations of the $\mathrm{Ag}^{2+}$ ion in the $\mathrm{Li}_{2} \mathrm{~B}_{4} \mathrm{O}_{7}$ lattice. The sets of principal-axis directions for the other seven orientations are obtained by applying rotations based on the symmetry elements of the lattice.

Figure 4 shows the ENDOR spectrum obtained from the $\mathrm{Ag}^{2+}$ ion in center $\mathrm{A}$ when the magnetic field is along the [001] direction. These data were taken at $15 \mathrm{~K}$ with the field fixed at $300.56 \mathrm{mT}$ (corresponding to the low-field EPR line of center A in Fig. 2, after accounting for the different microwave frequencies of the EPR and ENDOR cavities). As indicated by the accompanying stick diagrams, the lower frequency pair of ENDOR lines is assigned to the ${ }^{107} \mathrm{Ag}$ nuclei and the upper frequency pair of lines is assigned to the ${ }^{109} \mathrm{Ag}$ nuclei. The linewidths of these ENDOR signals are approximately $240 \mathrm{kHz}$. A similar set of ENDOR lines was observed in the $28-35 \mathrm{MHz}$ region when the magnetic field was fixed at $297.89 \mathrm{mT}$ (corresponding to the high-field EPR line associated with center B in Fig. 2). These latter results verify that center $\mathrm{B}$ is also a $\mathrm{Ag}^{2+}$ ion.

To first-order, the ENDOR spectrum from an $I=1 / 2$ nucleus consists of a pair of lines separated by $2 \nu_{\mathrm{N}}$ and centered on $\mathrm{A} / 2 .{ }^{32}$ Here, $\nu_{\mathrm{N}}$ is the Larmor frequency $\left(\nu_{\mathrm{N}}\right.$ $=\mathrm{g}_{\mathrm{N}} \beta_{\mathrm{N}} \mathrm{B} / \mathrm{h}$ ) and $\mathrm{A}$ is the hyperfine coupling parameter. Since the parameters $\nu_{\mathrm{N}}$ and A are both proportional to the nuclear magnetic moment, the two pairs of ENDOR lines in Fig. 4 allow the absolute identification of the responsible nuclei. The mid-points of the upper and lower pairs of lines in this spectrum are 41.29 and $35.67 \mathrm{MHz}$, respectively. This gives a ratio of 1.158 for these mid-points and agrees very well with the known ratio ${ }^{33}$ of 1.1518 for the magnetic moments of the two Ag isotopes. If second-order corrections

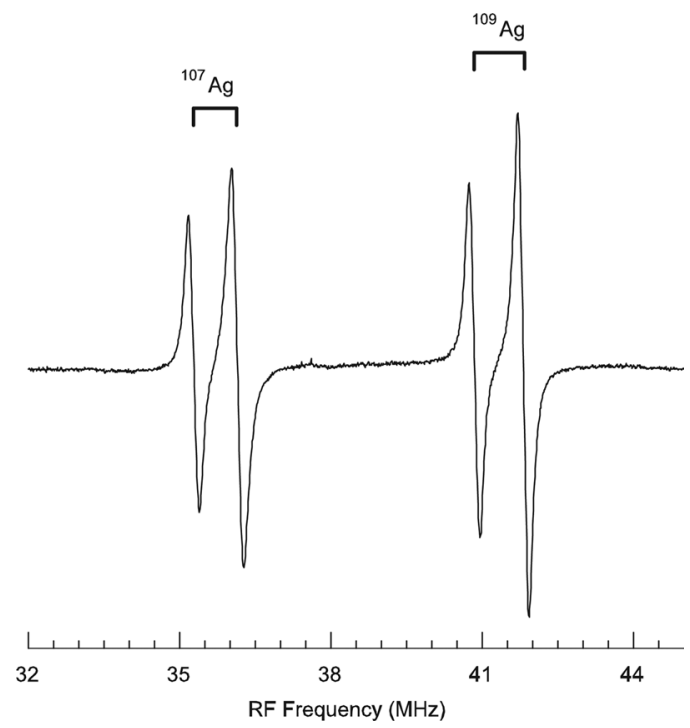

FIG. 4. ENDOR spectrum from center A, the isolated $\mathrm{Ag}^{2+}$ ion. These data were taken at $15 \mathrm{~K}$ while sitting on the low-field EPR line in Fig. 2. The magnetic field was along the [001] direction. Stick diagrams indicate the assignments of lines to the ${ }^{107} \mathrm{Ag}$ and ${ }^{109} \mathrm{Ag}$ nuclei. are taken into account, the separations of approximately 0.98 and $0.88 \mathrm{MHz}$ within the high and low frequency pairs of ENDOR lines, respectively, in Fig. 4 also agree with the known Ag nuclear magnetic moments. ${ }^{33}$

The ${ }^{107} \mathrm{Ag}$ and ${ }^{109} \mathrm{Ag}$ hyperfine matrices for center $\mathrm{A}$ were obtained from the ENDOR angular dependence data by fitting to a spin Hamiltonian having electron Zeeman, hyperfine, and nuclear Zeeman terms

$$
\mathbf{H}=\beta \mathbf{S} \cdot \mathbf{g} \cdot \mathbf{B}+\mathbf{I} \cdot \mathbf{A} \cdot \mathbf{S}-\mathrm{g}_{\mathrm{N}} \beta_{\mathrm{N}} \mathbf{I} \cdot \mathbf{B} .
$$

Values of the hyperfine parameters were determined independently for the two $\mathrm{Ag}$ isotopes. ENDOR spectra taken along the [001], [101], [100], and [110] directions were used to obtain the "best-fit" values for the six parameters describing each matrix. Input data consisted of 17 pairs of ENDOR lines taken with the magnetic field along these four directions. For each direction of magnetic field, a pair of ENDOR lines was obtained from each EPR line in the resolved doublets appearing in the EPR spectra. In total, 34 ENDOR frequencies and their associated magnetic field values were used to determine the six parameters. For a specific isotope, these data included two pairs of ENDOR lines from the [001] spectrum in Fig. 4, eight pairs of lines from the [101] spectrum, four pairs of lines from the [100] spectrum, and three pairs of lines from the [110] spectrum. Our leastsquares fitting procedure involved the repeated diagonalization of the $4 \times 4$ Hamiltonian matrix $(S=1 / 2, I=1 / 2)$ obtained from Eq. (2). The final "best-fit" values of the parameters describing the ${ }^{107} \mathrm{Ag}$ and ${ }^{109} \mathrm{Ag}$ matrices are listed in Table I. As was done for the $g$ matrix, the three Euler angles specifying the directions of the principal axes have been converted to $(\theta, \phi)$ pairs. The EPR and ENDOR angular dependences of center $\mathrm{A}$ for rotation of the magnetic field from [001] to [100] in the (010) plane are shown in Figs. 5 and 6 , respectively. The solid curves in these plots were computer-generated using the $g$ matrix and the ${ }^{109} \mathrm{Ag}$ hyperfine matrix in Table I. The discrete points in Figs. 5 and 6 are experimental data.

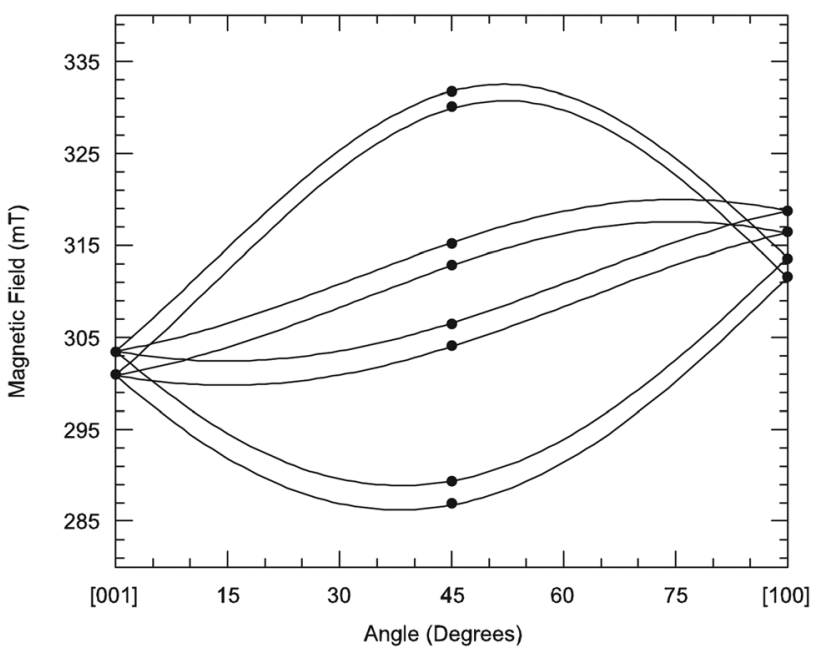

FIG. 5. EPR angular dependence in the (010) plane for center A. The solid lines were computer-generated using the $g$ and ${ }^{109} \mathrm{Ag}$ hyperfine parameters in Table I and a microwave frequency of $9.500 \mathrm{GHz}$. The discrete points are experimental data. 


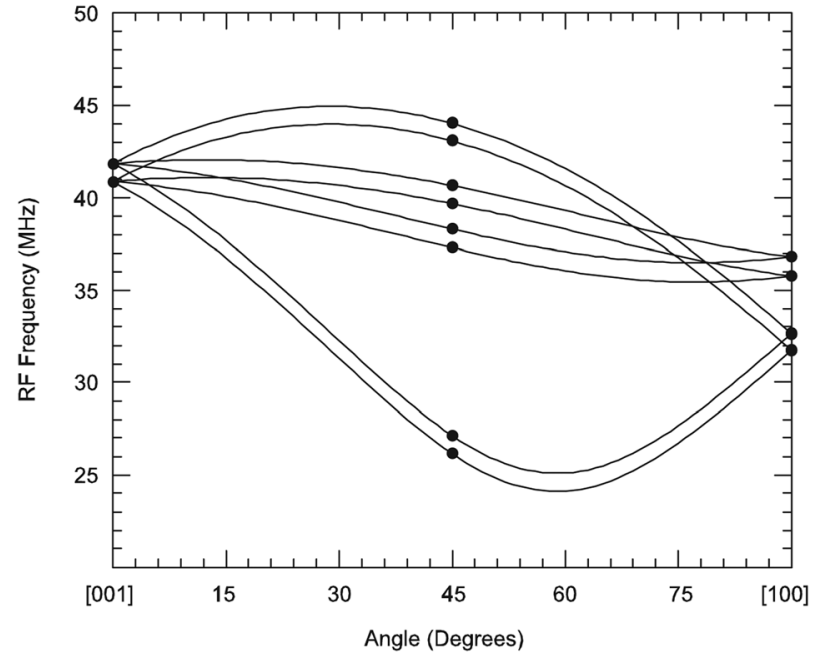

FIG. 6. ENDOR angular dependence in the (010) plane for center A. The solid lines were computer-generated using the $g$ and ${ }^{109} \mathrm{Ag}$ hyperfine parameters in Table I and a microwave frequency of $9.500 \mathrm{GHz}$. The discrete points are experimental data.

A detailed analysis of the principal-axis directions of the $g$ matrix and the hyperfine matrices listed in Table I is not attempted. In general, these directions provide information about the relative orientation in the lattice of the $\mathrm{Ag}^{2+} 4 \mathrm{~d}$ orbital occupied by the trapped hole. This minimum-energy orientation is governed primarily by the relative positions of the five nearest-neighbor oxygen ions (and perhaps also by nearby lithium and boron ions) around the substitutional $\mathrm{Ag}^{2+}$ ion. Relating the measured principal-axis directions to the surrounding ion positions is difficult because it is not known which one of the eight crystallographically equivalent defect sites corresponds to the sets of angles given in Table I. Local relaxation of the lattice, caused by the larger size of the $\mathrm{Ag}^{2+}$ ion, may also be a complicating factor. Thus, a detailed interpretation of the principal-axis directions for the $g$ matrix and the Ag hyperfine matrices must await the results of first-principles computational studies that can be correlated with our experimental results.

\section{B. Trapped electron center}

Figure 7 shows the dominant 16-line electronlike EPR spectrum produced in the $\mathrm{Ag}$-doped $\mathrm{Li}_{2} \mathrm{~B}_{4} \mathrm{O}_{7}$ crystal during the irradiation at room temperature with $\mathrm{x}$-rays. These data were taken at $40 \mathrm{~K}$ with the magnetic field along the [001] direction. Less intense signals from one or more additional unidentified defects are also present near 317, 340, and $363 \mathrm{mT}$. The primary 16 -line $\mathrm{S}=1 / 2 \mathrm{EPR}$ spectrum can be observed at room temperature and has very little angular dependence. As indicated by the stick diagrams above the spectrum in Fig. 7, this resolved hyperfine pattern is explained by primary interactions with two $\mathrm{I}=1 / 2$ nuclei (having nearly equal abundances and the sum being near 100\%) and a weaker interaction with one $\mathrm{I}=3 / 2$ nucleus (whose abundance is near $100 \%$ ). The ${ }^{107} \mathrm{Ag}$ and ${ }^{109} \mathrm{Ag}$ isotopes have similar magnetic moments (both have $\mathrm{I}=1 / 2$ ) and nearly equal abundances $(51.83 \%$ and $48.17 \%$, respectively). These properties of the ${ }^{107} \mathrm{Ag}$ and ${ }^{109} \mathrm{Ag}$ nuclei provide a consistent

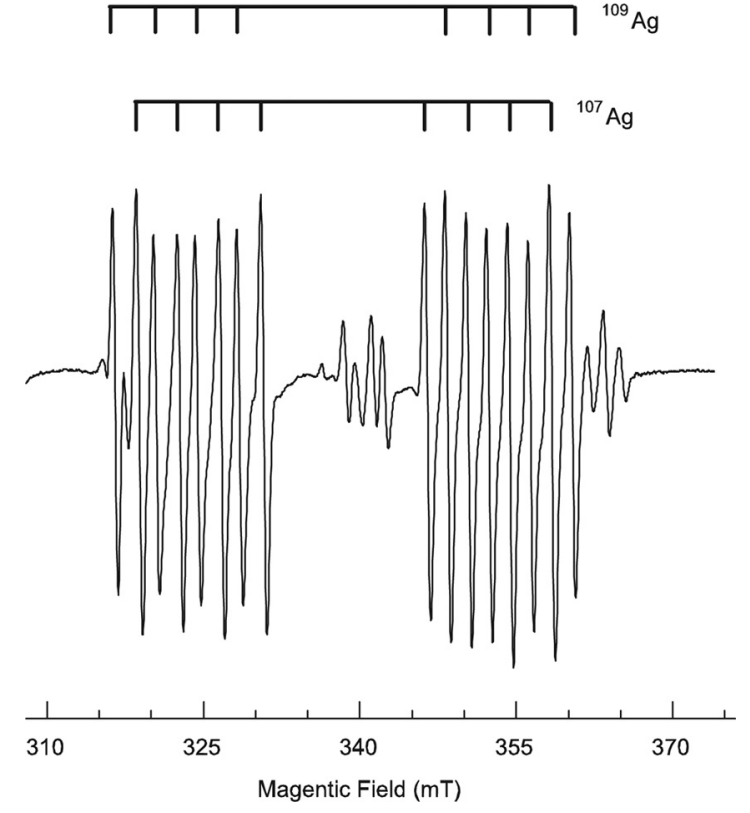

FIG. 7. EPR spectrum from the radiation-induced Ag-related electron trap in $\mathrm{Li}_{2} \mathrm{~B}_{4} \mathrm{O}_{7}$ crystal. The data were taken at $40 \mathrm{~K}$ with the magnetic field along the [001] direction. Stick diagrams indicate hyperfine interactions with ${ }^{107} \mathrm{Ag}$ and ${ }^{109} \mathrm{Ag}$ nuclei and with a neighboring $\mathrm{I}=3 / 2$ nucleus.

interpretation of the two primary hyperfine interactions in Fig. 7. ENDOR experiments on this EPR spectrum were not successful and the $I=3 / 2$ nucleus remains unidentified. The obvious choices for this third interacting nucleus are ${ }^{7} \mathrm{Li}$ or ${ }^{11} \mathrm{~B}$, since they are naturally present in the $\mathrm{Li}_{2} \mathrm{~B}_{4} \mathrm{O}_{7}$ lattice.

The $g$ value describing the EPR spectrum in Fig. 7 is $g_{c}=1.9930 \pm 0.0001$, and the hyperfine constants are $\mathrm{A}_{\mathrm{c}}=770 \mathrm{MHz}$ for the ${ }^{107} \mathrm{Ag}$ nucleus and $\mathrm{A}_{\mathrm{c}}=887 \mathrm{MHz}$ for the ${ }^{109} \mathrm{Ag}$ nucleus. The hyperfine constant is $\mathrm{A}_{\mathrm{c}}=110 \mathrm{MHz}$ for the unidentified $I=3 / 2$ nucleus. Error limits for these three $A_{c}$ values are estimated to be $\pm 0.5 \mathrm{MHz}$. The ratio of the measured hyperfine constants for the $\mathrm{Ag}$ nuclei is ${ }^{109} \mathrm{Ag} /{ }^{107} \mathrm{Ag}=1.1519$. This agrees very well with the known ratio $^{33}$ of 1.1518 for the magnetic moments of the Ag isotopes. A careful inspection of the spectrum in Fig. 7 shows that the centers of the ${ }^{107} \mathrm{Ag}$ and ${ }^{109} \mathrm{Ag}$ hyperfine patterns are shifted relative to each other by approximately $0.15 \mathrm{mT}$. This effect is not due to different $g_{c}$ values for the two isotopes. Instead, the observed relative shift depends on the magnitude of the hyperfine parameters and results from second-order contributions in the spin Hamiltonian. Specifically, the ${ }^{109} \mathrm{Ag}$ isotope has a larger $\mathrm{A}_{\mathrm{c}}$ value and thus its spectrum is shifted slightly to lower field even though its $g_{c}$ value is the same as the ${ }^{107} \mathrm{Ag}$ spectrum.

We use the measured values of the hyperfine parameters to establish a model for the electron trap in the Ag-doped $\mathrm{Li}_{2} \mathrm{~B}_{4} \mathrm{O}_{7}$ crystal. The ${ }^{107} \mathrm{Ag}$ and ${ }^{109} \mathrm{Ag}$ hyperfine patterns associated with this defect have very large splittings and little angular dependence. Together, these are general characteristics of a $\mathrm{Ag}^{0}$ atom $\left(4 \mathrm{~d}^{10} 5 \mathrm{~s}^{1}\right)$ that forms when a $\mathrm{Ag}^{+}$ion $\left(4 \mathrm{~d}^{10}\right)$ traps an extra electron. Numerous examples of $\mathrm{Ag}^{0}$ atoms have been reported in the literature. ${ }^{30,34-36}$ The Ag hyperfine splittings $\left(887 \mathrm{MHz}\right.$ for $\left.{ }^{109} \mathrm{Ag}\right)$ observed in Fig. 7, however, are approximately a factor of two smaller than the 
typical splittings reported for $\mathrm{Ag}^{0}$ atoms $(1300-2100 \mathrm{MHz}$ for $\left.{ }^{109} \mathrm{Ag}\right) .{ }^{36}$ Morten and Preston ${ }^{37,38}$ predict that $\mathrm{a}^{\mathrm{O}}{ }^{0}$ atom will have an isotropic hyperfine interaction of $1831 \mathrm{MHz}$ for the ${ }^{109} \mathrm{Ag}$ isotope. This means, in our case, that about $50 \%$ of the unpaired spin is in a $5 \mathrm{~s}$ orbital on the Ag ion, with the remaining portion of the unpaired spin on adjacent ions. The hyperfine interactions in Fig. 7 arising from the $I=3 / 2$ nucleus suggest that much of the remaining spin density may be located on this ion. Thus, we assign the EPR spectrum in Fig. 7 to a trapped electron shared between an interstitial $\mathrm{Ag}$ ion and a nearby substitutional $\mathrm{I}=3 / 2$ ion (either a neighboring ${ }^{7} \mathrm{Li}$ or ${ }^{11} \mathrm{~B}$ ion). Some of the unpaired spin density may also be distributed on nearby oxygen ions. Although only about half of the trapped electron is localized on the silver ion in a $5 \mathrm{~s}$ orbital, we will refer to this electron trap as a $\mathrm{Ag}^{0}$ atom in Sec. III C. A less likely alternative model for the 16line trapped electron center in $\mathrm{Li}_{2} \mathrm{~B}_{4} \mathrm{O}_{7}$ is to have a $\mathrm{Ag}^{+}$ion substituting for a $\mathrm{Li}^{+}$ion trap the extra electron and share the unpaired spin with a neighboring $\mathrm{Li}$ or B ion.

\section{Thermoluminescence}

A series of isochronal pulsed anneals at progressively higher temperatures was used to determine the thermal stabilities of the radiation-induced defects observed with EPR. Figure 8 shows the results obtained by monitoring the intensities of the EPR signals from the electron trap and the isolated hole trap (center A). The following procedure was employed. First, these EPR spectra were recorded at $30 \mathrm{~K}$ after the crystal was irradiated at room temperature for $10 \mathrm{~min}$ with $\mathrm{x}$-rays. Next, the crystal was removed from the microwave cavity and held for $3 \mathrm{~min}$ at $50{ }^{\circ} \mathrm{C}$ in a bench-top furnace. Then, the crystal was returned to $30 \mathrm{~K}$ in the microwave cavity, and the EPR spectra were again recorded. This procedure of warming the sample to successively higher temperatures was repeated

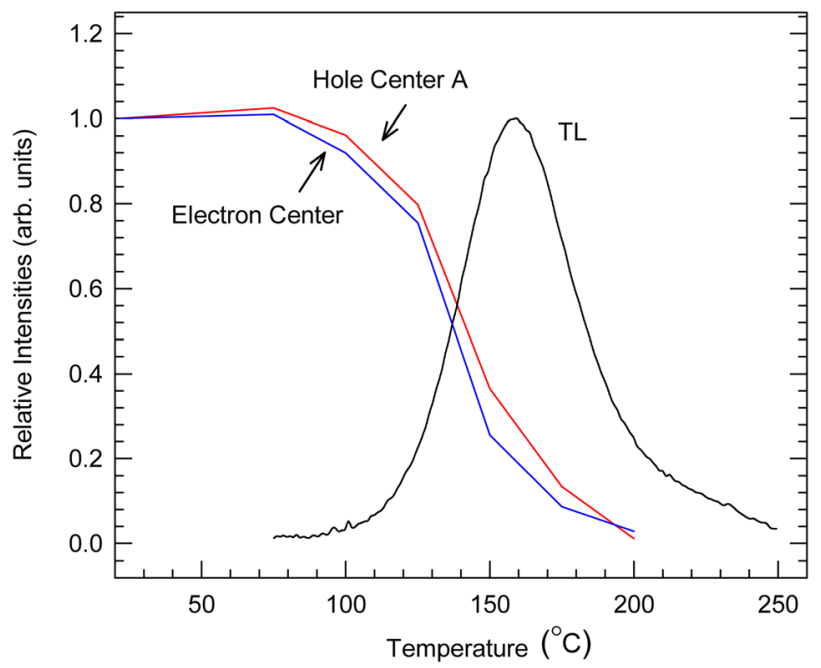

FIG. 8. (Color online) Thermal stabilities of the electron trap and the isolated $\mathrm{Ag}^{2+}$ hole trap (center A) obtained by monitoring their EPR spectra during a sequence of isochronal pulse anneals. Also plotted is the thermoluminescence "glow" curve obtained by monitoring the total light output in the near-ultraviolet region. The effective heating rates are different for the two experiments (see the text for details). in $25^{\circ} \mathrm{C}$ steps from 50 to $200^{\circ} \mathrm{C}$. After each anneal, the sample was returned to $30 \mathrm{~K}$ where the intensities of the EPR signals were monitored. The data in Fig. 8 show that the EPR signals from the electron trap and the isolated hole trap (center A) thermally decay in the same temperature range. The perturbed hole trap (center B) also thermally decays in this same temperature range. Approximately half of the traps have emptied by $140{ }^{\circ} \mathrm{C}$ and nearly all of them have released the trapped charge by $200^{\circ} \mathrm{C}$.

Thermoluminescence (TL) data taken from our $\mathrm{Ag}$ doped $\mathrm{Li}_{2} \mathrm{~B}_{4} \mathrm{O}_{7}$ crystal are shown in Fig. 8. Light emitted in the near-ultraviolet region is monitored. The heating rate is $0.1{ }^{\circ} \mathrm{C} / \mathrm{s}$, and the peak of the TL curve appears near $160{ }^{\circ} \mathrm{C}$. This heating rate (slowest available for the TL apparatus) was chosen in order to "mimic" the "averaged" heating rate used to obtain the EPR pulsed annealing results plotted in Fig. 8. Although our EPR and TL results in Fig. 8 were obtained under different experimental conditions, they are in good agreement. Thus, we conclude that the $160{ }^{\circ} \mathrm{C}$ TL peak is directly connected with the disappearance of the EPR signals representing the $\mathrm{Ag}^{2+}$ hole traps and the $\mathrm{Ag}^{0}$ electron trap. The TL experiment was repeated with increased heating rates, and as expected, ${ }^{39}$ the peak in the emitted light intensity shifted to higher temperatures. For a heating rate of 0.5 ${ }^{\circ} \mathrm{C} / \mathrm{s}$, the TL peak appeared at $177{ }^{\circ} \mathrm{C}$. The approximation introduced by Randall and Wilkins ${ }^{40}$ provides a simple method to estimate the activation energy associated with a TL peak. In this approximation, the thermal activation energy is given by $\mathrm{E} \approx 25 \mathrm{kT}_{\mathrm{m}}$, where $\mathrm{T}_{\mathrm{m}}$ is the peak temperature. Our TL peak varies from 433 to $450 \mathrm{~K}$, depending on the heating rate, and the corresponding estimate of the activation energy varies from 0.93 to $0.97 \mathrm{eV}$. There is an uncertainty of at least $20 \%$ in the activation energies obtained using this approximation. For comparison, Ege et al. ${ }^{3}$ observed a similar TL peak near $173{ }^{\circ} \mathrm{C}$ with a heating rate of $1{ }^{\circ} \mathrm{C} / \mathrm{s}$ in $\mathrm{Li}_{2} \mathrm{~B}_{4} \mathrm{O}_{7}$ samples doped with $\mathrm{Cu}, \mathrm{Ag}$, and $\mathrm{P}$ and extracted a value of $1.13 \mathrm{eV}$ for the activation energy. (Note: $\mathrm{Cu}$ and $\mathrm{P}$ impurities were not added to the $\mathrm{Li}_{2} \mathrm{~B}_{4} \mathrm{O}_{7}$ crystal used in the present study.)

The mechanism responsible for the TL peak in Fig. 8 can be simply described by the following sequence of events. When the crystal is exposed at room temperature to ionizing radiation, holes are trapped in the form of substitutional $\mathrm{Ag}_{\mathrm{s}}{ }^{2+}$ ions and electrons are trapped in the form of interstitial $\mathrm{Ag}_{\mathrm{i}}{ }^{0}$ atoms ${ }^{41}$

$$
\begin{gathered}
\mathrm{Ag}_{\mathrm{s}}^{+}+\mathrm{h}^{+} \longrightarrow \mathrm{Ag}_{\mathrm{s}}^{2+}, \\
\mathrm{Ag}_{\mathrm{i}}^{+}+\mathrm{e}^{-} \longrightarrow \mathrm{Ag}_{\mathrm{i}}^{0} .
\end{gathered}
$$

As the crystal is warmed above room temperature, the trapped holes and electrons recombine.

$$
\mathrm{Ag}_{\mathrm{s}}^{2+}+\mathrm{Ag}_{\mathrm{i}}^{0} \longrightarrow \mathrm{Ag}_{\mathrm{s}}^{+}+\mathrm{Ag}_{\mathrm{i}}^{+}+\text {emitted photon }(\mathrm{h} \nu) .
$$

The question of the recombination site remains open since the relative thermal stabilities of the trapped holes and trapped electrons are not known (when one type of trap disappears during warming, the other type of trap also disappears). There are two possibilities, the TL emission process 
is initiated either by hole release or by electron release. If the trapped holes are the first to become thermally unstable, the released holes will move through the crystal and recombine with the trapped electrons at the electron-trapping sites. Conversely, if the trapped electrons are the first to become thermally unstable, the released electrons will move through the crystal and recombine with the trapped holes at the holetrapping sites.

\section{SUMMARY}

Electron and hole traps have been identified in Agdoped single crystals of $\mathrm{Li}_{2} \mathrm{~B}_{4} \mathrm{O}_{7}$ using EPR and ENDOR techniques. During an exposure at room temperature to ionizing radiation, holes are trapped at substitutional $\mathrm{Ag}^{+}$ions and form paramagnetic $\mathrm{Ag}^{2+}$ ions. At the same time, electrons are trapped at interstitial $\mathrm{Ag}^{+}$ions and form defects that have the unpaired spin shared by the interstitial ion and a neighboring substitutional ion (either Li or B). A complete set of spin-Hamiltonian parameters are determined for the isolated substitutional $\mathrm{Ag}^{2+}$ trapped holes. The trapped electron spectrum has little angular dependence and only its [001] parameters are provided. An intense thermoluminescence (TL) peak is observed near $160{ }^{\circ} \mathrm{C}$ when the thermally released electrons and holes recombine. The emitted light is in the near ultraviolet, but the recombination site is not identified.

\section{ACKNOWLEDGMENTS}

Support for this study at the Air Force Institute of Technology was provided by Grants HDTRA1-07-1-0008 and BRBAA08-I-2-0128 from the Defense Threat Reduction Agency, support at West Virginia University was provided by Grant DMR-0804352 from the National Science Foundation, and support at the Institute of Physical Optics was provided through Project 0109U001063 and STCU Project 4947 from the Ministry of Education and Sciences of the Ukraine. The views expressed in this article are those of the authors and do not necessarily reflect the official policy or position of the Air Force, the Department of Defense, or the United States Government.

${ }^{1}$ Z. Xiong, Q. Tang, X. Xiong, D. Luo, and P. Ding, Radiat. Meas. 46, 323 (2011).

${ }^{2}$ B. T. Huy, V. X. Quang, and H. T. B. Chau, J. Lumin. 128, 1601 (2008).

${ }^{3}$ A. (Türkler) Ege, E. Ekdal, T. Karali, and N. Can, Radiat. Meas. 42, 1280 (2007).

${ }^{4}$ N. Can, T. Karali, P. D. Townsend, and F. Yildız, J. Phys. D: Appl. Phys. 39, 2038 (2006).

${ }^{5}$ V. T. Adamiv, O. T. Antonyak, Ya. V. Burak, M. S. Pidzyrailo, and I. M. Teslyuk, Funct. Mater. 12, 278 (2005).

${ }^{6}$ M. Prokic, Radiat. Prot. Dosim. 100, 265 (2002).

${ }^{7}$ L. Singh, V. Chopra, and S. P. Lochab, J. Lumin. 131, 1177 (2011).

${ }^{8}$ Babita Tiwari, N. S. Rawat, D. G. Desai, S. G. Singh, M. Tyagi, P. Ratna, S. C. Gadkari, and M. S. Kulkarni, J. Lumin. 130, 2076 (2010).
${ }^{9}$ V. T. Adamiv, Ya. V. Burak, D. J. Wooten, J. McClory, J. Petrosky, I. Ketsman, J. Xiao, Ya. B. Losovyj, and P. A. Dowben, Materials 3, 4550 (2010).

${ }^{10}$ J. K. Srivastava and S. J. Supe, J. Phys. D: Appl. Phys. 22, 1537 (1989).

${ }^{11}$ J. Xu, S. Fan, and B. Lu, J. Cryst. Growth 264, 260 (2004).

${ }^{12}$ N. Tsutsui, Y. Ino, K. Imai, N. Senguttuvan, and M. Ishii, J. Cryst. Growth 229, 283 (2000).

${ }^{13}$ N. Tsutsui, Y. Ino, K. Imai, N. Senguttuvan, and M. Ishii, J. Cryst. Growth 211, 271 (2000).

${ }^{14}$ Sangeeta, K. Chennakesavulu, D. G. Desai, S. C. Sabharwal, M. Alex, and M. D. Ghodgaonkar, Nucl. Instr. Meth. A 571, 699 (2007).

${ }^{15}$ Ya. V. Burak, V. T. Adamiv, I. M. Teslyuk, and V. M. Shevel, Radiat. Meas. 38, 681 (2004).

${ }^{16}$ T. Nakamura, M. Katagiri, K. Soyama, M. Ukibe, T. Ikeuchi, and M. Ohkubo, Nucl. Instr. Meth. A 529, 402 (2004).

${ }^{17}$ T. Nakamura, M. Katagiri, M. Ukibe, T. Ikeuchi, and M. Ohkubo, Nucl. Instr. Meth. A 520, 67 (2004).

${ }^{18}$ M. W. Swinney, J. W. McClory, J. C. Petrosky, Shan Yang, A. T. Brant, V. T. Adamiv, Ya. V. Burak, P. A. Dowben, and L. E. Halliburton, J. Appl. Phys. 107, 113715 (2010).

${ }^{19}$ G. Corradi, V. Nagirnyi, A. Watterich, A. Kotlov, and K. Polgár, Journal of Physics: Conference Series 249, 012008 (2010).

${ }^{20}$ G. Corradi, V. Nagirnyi, A. Kotlov, A. Watterich, M. Kirm, K. Polgar, A. Hofstaetter, and M. Meyer, J. Phys.: Condens. Matter 20, 025216 (2008).

${ }^{21}$ G. Corradi, A. Watterich, K. Polgár, V. Nagirnyi, A. Hofstaetter, L. G. Rakitina, and M. Meyer, Phys. Stat. Sol. (c) 4, 1276 (2007).

${ }^{22}$ J. Xiao, N. Lozova, Ya. B. Losovyj, D. Wooten, I. Ketsman, M. W. Swinney, J. Petrosky, J. McClory, Ya. V. Burak, V.T. Adamiv, A. T. Brant, and P. A. Dowben, Appl. Surface Science 257, 3399 (2011).

${ }^{23}$ A. Senyshyn, B. Schwarz, T. Lorenz, V. T. Adamiv, Ya. V. Burak, J. Banys, R. Grigalaitis, L. Vasylechko, H. Ehrenberg, and H. Fuess, J. Appl. Phys. 108, 093524 (2010).

${ }^{24}$ V. T. Adamiv, Ya. V. Burak, and I. M. Teslyuk, J. Alloys Compd. 475, 869 (2009).

${ }^{25}$ N. Sennova, R. S. Bubnova, G. Cordier, B. Albert, S. K. Filatov, and L. Isaenko, Z. Anorg. Allg. Chem. 634, 2601 (2008).

${ }^{26}$ S. F. Radaev, L. A. Muradyan, L. F. Malakhova, Ya. V. Burak, and V. I. Simonov, Kristallografiya 34, 1400 (1989).

${ }^{27}$ Jan Krogh-Moe, Acta Crystallogr. 24, 179 (1968).

${ }^{28}$ B. E. Kananen, M.S. thesis, Air Force Institute of Technology, 2011, pp. 34-35.

${ }^{29}$ W. L. Li, X. M. Li, W. L. Feng, W. J. Yang, and C. Y. Tao, Spectrochim. Acta A 79, 1308 (2011)

${ }^{30}$ W. Hong, D. Perlov, and L. E. Halliburton, J. Phys. D: Appl. Phys. 36, 2605 (2003).

${ }^{31}$ K. Chandrasekharan and V. S. Murty, Physica B 205, 349 (1995).

${ }^{32}$ J.-M. Spaeth and H. Overhof, Point Defects in Semiconductors and Insulators: Determination of Atomic and Electronic Structure from Paramagnetic Hyperfine Interactions (Springer-Verlag, Heidelberg, 2003), pp. 174175 .

${ }^{33}$ J. A. Weil and J. R. Bolton, Electron Paramagnetic Resonance: Elementary Theory and Practical Applications, 2nd ed. (John Wiley \& Sons, Hoboken, NJ, 2007), p. 581.

${ }^{34}$ R. I. Mashkovtsev, L. V. Kulik, and V. P. Solntsev, J. Struct. Chem. 51, 869 (2010).

${ }^{35}$ J. A. Aramburu, M. Moreno, I. Cabria, M. T. Barriuso, C. Sousa, C. de Graaf, and F. Illas, Phys. Rev. B 62, 13356 (2000).

${ }^{36}$ S. V. Nistor, D. Schoemaker, and I. Ursu, Phys. Stat. Sol. B 185, 9 (1994).

${ }^{37}$ J. R. Morton and K. F. Preston, J. Magn. Reson. 30, 577 (1978).

${ }^{38}$ James A. J. Fitzpatrick, Frederick R. Manby, and Colin M. Western, J. Chem. Phys. 122, 084312 (2005).

${ }^{39}$ A. (Türkler) Ege, E. Ekdal, T. Karali, N. Can, and M. Prokic, Meas. Sci. Technol. 18, 889 (2007).

${ }^{40}$ J. T. Randall and M. H. F. Wilkins, Proc. R. Soc. London, Ser. A 184, 366 (1945).

${ }^{41}$ Ya. V. Burak, V. T. Adamiv, O. T. Antonyak, S. Z. Malynych, M. S. Pidzyrailo, and I. M. Teslyuk, Ukr. J. Phys. 50, 1153 (2005). 